\title{
Rethinking the Approach to Preclinical Models of Anorexia Nervosa
}

\author{
Marie François ${ }^{1} \cdot$ Lori M. Zeltser ${ }^{1,2}$
}

Accepted: 1 December 2021 / Published online: 11 February 2022

(c) The Author(s) 2022

\begin{abstract}
Purpose of Review The goal of this review is to describe how emerging technological developments in pre-clinical animal research can be harnessed to accelerate research in anorexia nervosa (AN).

Recent Findings The activity-based anorexia (ABA) paradigm, the best characterized animal model of AN, combines restricted feeding, excessive exercise, and weight loss. A growing body of evidence supports the idea that pathophysiological weight loss in this model is due to cognitive inflexibility, a clinical feature of AN. Targeted manipulations that recapitulate brain changes reported in AN - hyperdopaminergia or hyperactivity of cortical inputs to the nucleus accumbens - exacerbate weight loss in the ABA paradigm, providing the first evidence of causality.

Summary The power of preclinical research lies in the ability to assess the consequences of targeted manipulations of neuronal circuits that have been implicated in clinical research. Additional paradigms are needed to capture other features of AN that are not seen in ABA.
\end{abstract}

Keywords Activity-based anorexia - Animal models $\cdot$ Anorexia nervosa $\cdot$ Cognitive inflexibility Perseverative behavior . Neural circuits

\section{Introduction}

A suite of newly developed tools in pre-clinical (animal) models can help overcome several obstacles to understanding brain mechanisms of anorexia nervosa (AN). Advances in current methods can characterize, map, and manipulate neural circuits with unprecedented cellular precision [1-3]. Application of these cutting-edge tools is leading to rapid advances in the understanding of many psychiatric disorders, such as schizophrenia and autism spectrum disorder [4]. To leverage these tools to study AN, relevant preclinical models are needed. Historically, animal models have attempted to recapitulate as many features of AN as possible. In this review, we use the best characterized preclinical model of $\mathrm{AN}$, activity-based anorexia (ABA), to illustrate limitations

This article is part of the Topical Collection on Eating Disorders

Lori M. Zeltser

lz146@cumc.columbia.edu

1 Division of Molecular Genetics, Naomi Berrie Diabetes Center, Columbia University Irving Medical Center, New York, USA

2 Department of Pathology and Cell Biology, Columbia University Irving Medical Center, New York, USA in the traditional approach to animal models and to highlight emerging approaches that use the ABA model to identify circuits and molecular pathways responsible for discrete aspects of AN.

\section{ABA Paradigm: Classical Approaches}

In the ABA paradigm, rodents are provided with continuous access to a running wheel and are then exposed to timerestricted feeding, such that access to food is confined to the first $1-2 \mathrm{~h}$ of the dark phase. Instead of eating during this limited feeding period, some rodents paradoxically choose to run; this leads to a precipitous decrease in body weight and decrease in survival over the next few days [5]. This relatively simple model captures features of $\mathrm{AN}$, including increased susceptibility in adolescence, physiological and hormone changes associated with weight loss, excessive exercise, and caloric restriction (although it should be acknowledged that limited access to food is not the case in humans) [6]. Researchers have particularly touted the ABA as a powerful system to study the interaction between hyperactivity, caloric restriction and weight loss that is observed in $\mathrm{AN}$ [7-10]. 
Similar to clinical research, rodent studies compare ABA groups with unaffected "healthy comparison" groups. The comparison groups consist of ad libitum fed animals; a weight-recovered group is sometimes included as well. These studies demonstrate that, like in patients with $\mathrm{AN}, \mathrm{ABA}$ rodents have decreased brain volume that is reversed by re-feeding [11-14, 15•]. Weight loss is also associated with increased markers of oxidative stress in the prefrontal cortex that is reversed by weight restoration [16]. The ABA model provided new insights into the impact of AN on the brain by identifying reductions in astrocyte number and proliferation in the cerebral cortex without a change in neuronal number [15•]. This finding challenges the existing assumption that deficits in the grey matter and white matter of patients with AN stemmed from decreased neurogenesis [17] and introduces a new potential mechanistic hypothesis involving a role for astrocytes in AN. Animal models, including ABA, have the potential to provide ways of distinguishing components of illness and differential brain effects. For example, by including control groups that may disentangle effects of exercise and caloric restriction on the brain.

A control group can be exposed to exercise alone, without weight loss, or to restricted feeding only, which produces the same amount of weight loss, but with less associated mortality [18, 19, 20•]. Comparisons between mice exposed to restricted feeding only vs. the ABA paradigm reveal that patterns of neuronal activation in the hypothalamus are largely driven by restricted feeding $[21,22]$. While the inclusion of additional control groups is very powerful, it is also laborious.

Another strategy involves exposing a large cohort of animals through the ABA paradigm and then comparing the group that develops ABA (vulnerable) versus the group that does not (resilient). Vulnerable mice rapidly lose body weight within the first few days, while resilient mice adapt to an initial period of weight loss and maintain a stable weight $[20 \bullet, 23]$. Because the animals experience the same experimental conditions, it is easier to identify factors driving vulnerability. Some groups have shown that baseline running activity predicts susceptibility to ABA [24-26, 27••], but translating this observation to human behavior and physiology is not straightforward. Rodents adapt to a schedule of restricted feeding by increasing their locomotor activity immediately before access to food is expected [28]. This phenomenon, called "food anticipatory behavior," reflects an evolutionarily advantageous adaptation to increase motivation to seek food when it is available in limited supplies [29]. Thus, food anticipatory behavior promotes caloric intake under restricted access paradigms and is associated with resilience to the ABA [20•]. On the other hand, some have posited that excessive running in the ABA model reflects a pathophysiological expansion of food anticipatory behavior
[30]. Greater resolution in activity measurements is needed to resolve this issue.

Changes in synaptic transmission in the hippocampus are associated with vulnerability to ABA [31]. For example, there is a strong negative correlation between hippocampal expression of the glutamate transporter GLT1 and running wheel activity and weight loss in the ABA model [32•]. Loss of GLT1 function is sufficient to enhance wheel

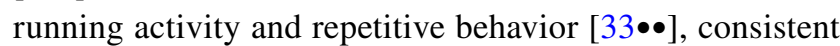
with the idea that the resulting increase in glutamate transmission promotes ABA vulnerability. At the same time, the two primary manipulations in the ABA model, voluntary exercise and caloric restriction, are associated with increases in hippocampal GLT1 expression and glutamate uptake that are predicted to decrease glutamate transmission $[34,35]$. Thus, vulnerability to ABA could reflect low baseline levels of GLT1 and/or the failure to appropriately upregulate its expression in response to caloric restriction or activity. These animal models can identify behaviors, physiological adaptations, or biomarkers of susceptibility.

\section{ABA Paradigm: Moving Beyond Correlation to Causation}

New powerful techniques can be used to physically target a specific brain region, and genetic tools can target a specific neuronal population within that region. These techniques can be used to replicate neuronal changes that have been observed in neuroimaging studies in patients with AN. For example, increased binding to the D2/D3 dopamine receptor $(\mathrm{D} 2 \mathrm{R} / \mathrm{D} 3 \mathrm{R})$ is observed in the ventral striatum of women who recovered from AN [36]. In animals, this finding is mimicked by overexpression of the D2R autoreceptor exclusively in the nucleus accumbens. This targeted manipulation produces localized hyperdopaminergia [37, 38] and accelerates weight loss in the ABA paradigm in females, but not in males [39••]. These findings are consistent with reports that hyperdopaminergia produced by genetic reductions in dopamine transporter expression increases susceptibility to the ABA paradigm in female mice [20•]. Understanding how D2R circuits influence metabolic adaptation to restricted feeding could provide novel insights into the mechanism underlying sex differences in susceptibility to AN [40, 41]. Moreover, further characterization of this overexpression model using other behavioral and physiological assays can help to identify additional features of AN that might be caused by increased D2R in the ventral striatum.

Neural circuits can also be manipulated with emerging neuroscience techniques. Pathway specific "chemogenetic" tools have yielded a particularly compelling experimental story relevant for AN $[27 \bullet \bullet]$. Chemogenetic tools are used 
to modulate activity of projections from the prefrontal cortex to the nucleus accumbens. This circuit was identified in human neuroimaging studies to show abnormal connectivity in acute AN and after weight restoration [42]. Stimulation of this circuit increases perseverative wheel running behavior

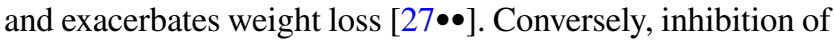
this pathway improves flexibility during early reversal learning by reducing perseverative responding and promotes food

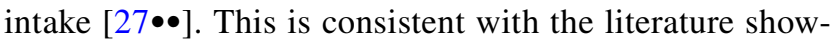
ing that this circuit modulates set shifting in rodents [43, 44]. Cognitive inflexibility is also seen in patients with AN [45-47] and in rodents in the ABA paradigm [48].

These observations raise the possibility that the ABA model captures a failure to adapt to restricted access to food in the face of preservative running behavior. In support of this idea, acclimation to restricted feeding before providing access to the running wheel suppresses hyperactivity in the ABA paradigm [19]. Additionally, the excessive running and weight loss phenotypes of the ABA model are no longer observed when the total time with access to food is distributed across several shorter time periods (four 15-min sessions or two 30-min sessions vs. one 1-h session) [49]. Since humans spread their daily food intake across multiple meals, studies of circuits regulating feeding behavior per se in the ABA model may not be translationally relevant. On the other hand, the perseverative running could reflect a broader pattern of repetitive behavior, as mice exposed to the ABA paradigm exhibit other perseverative behaviors, such as increased marble burying as well [50], the most reliable assay to measure perseverative behavior in rodents [51-53].

The ABA paradigm has been criticized for its failure to recapitulate aspects of AN such as sex differences, genetic susceptibility, anxiety, social phobias, harm avoidance and fear, and avoidance of dietary fat [6]. It may be that narrowing the scope of what ABA is modeling can be viewed as a strength, because it accelerates direct comparisons with observations in humans. Recapitulation of the link between D2R overexpression and hyperactivity of prefrontal cortical to nucleus accumbens connections and cognitive inflexibility

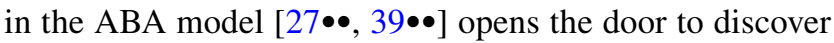
the molecular pathways underlying this key feature of AN [45-47]. If the ABA paradigm does, in fact, primarily capture cognitive inflexibility and perseverative behavior, circuits identified in this model could contribute to both AN and obsessive-compulsive disorder (OCD) [54, 55]. In support of this idea, compulsivity contributes to the variance in eating disorders and OCD and is associated with gray matter volume in the orbitofrontal cortex, ventral striatum, and dorsolateral prefrontal cortex [56]. Neural circuits and molecular pathways uncovered in mouse models could lead to the identification of novel transdiagnostic therapeutic targets.

This review focuses on recent evidence that the ABA paradigm captures both behavioral and neuronal signatures associated with cognitive inflexibility and preservative behaviors observed in AN. This does not exclude the possibility that it can also be used to model metabolic [57-59] or psychological [60-63] adaptations to chronic food restriction and weight loss that promote susceptibility to AN [64-67]. The studies highlighted here provide a roadmap for leveraging the current neuroscience toolbox to demonstrate construct validity in animal models of AN.

\section{Conclusions}

To date, the goal of preclinical studies has been to develop a model that recapitulates as many of the features of AN as possible. While additional control groups in rodents can be used to parse causative factors from secondary consequences of $\mathrm{AN}$, in the end, the sheer complexity of these paradigms makes these analyses extremely expensive and tedious. The power of preclinical research lies in the ability to assess the consequences of targeted manipulations of neuronal circuits that have been implicated in clinical research. Therefore, the primary obstacle to preclinical studies of AN is not the lack of a unitary model that fully recapitulates the disease in humans, but rather the absence of complementary models that capture other features of AN that are not seen in ABA. Better communication between preclinical and clinical researchers is needed to develop translationally relevant paradigms that can be used in cross-species studies to examine how changes in specific brain circuits influence susceptibility to AN.

Funding This work was funded by the NIH 1R01 MH113353 (L.M.Z.), the Klarman Family Foundation for Eating Disorders Research (L.M.Z.), and the Russell Berrie Foundation (L.M.Z.).

\section{Compliance with Ethical Standards}

Conflict of Interest The authors declare no competing interests.

Open Access This article is licensed under a Creative Commons Attribution 4.0 International License, which permits use, sharing, adaptation, distribution and reproduction in any medium or format, as long as you give appropriate credit to the original author(s) and the source, provide a link to the Creative Commons licence, and indicate if changes were made. The images or other third party material in this article are included in the article's Creative Commons licence, unless indicated otherwise in a credit line to the material. If material is not included in the article's Creative Commons licence and your intended use is not permitted by statutory regulation or exceeds the permitted use, you will need to obtain permission directly from the copyright holder. To view a copy of this licence, visit http://creativecommons.org/licenses/by/4.0/. 


\section{References}

Papers of particular interest, published recently, have been highlighted as:

- Of importance

$\bullet$ Of major importance

1. Renier N, Wu Z, Simon DJ, Yang J, Ariel P, Tessier-Lavigne M. iDISCO: a simple, rapid method to immunolabel large tissue samples for volume imaging. Cell. 2014;159(4):896-910. https:// doi.org/10.1016/j.cell.2014.10.010.

2. Renier N, Adams EL, Kirst C, Wu Z, Azevedo R, Kohl J, et al. Mapping of brain activity by automated volume analysis of immediate early genes. Cell. 2016;165(7):1789-802. https:// doi.org/10.1016/j.cell.2016.05.007.

3. Yook JS, Kim J, Kim J. Convergence circuit mapping: genetic approaches from structure to function. Front Syst Neurosci. 2021;15: 688673. https://doi.org/10.3389/fnsys.2021.688673.

4. Seo DO, Motard LE, Bruchas MR. Contemporary strategies for dissecting the neuronal basis of neurodevelopmental disorders. Neurobiol Learn Mem. 2019;165: 106835. https://doi.org/10. 1016/j.nlm.2018.03.015.

5. Routtenberg A, Kuznesof AW. Self-starvation of rats living in activity wheels on a restricted feeding schedule. J Comp Physiol Psychol. 1967;64(3):414-21.

6. Schalla MA, Stengel A. Activity based anorexia as an animal model for anorexia nervosa-a systematic review. Front Nutr. 2019;6:69. https://doi.org/10.3389/fnut.2019.00069.

7. Epling WF, Pierce WD, Stefan L. A theory of activity-based anorexia. Int J Eat Disord. 1983;3:27-46.

8. Davis C. Eating disorders and hyperactivity: a psychobiological perspective. Can J Psychiatry. 1997;42(2):168-75.

9. Davis C, Kaptein S. Anorexia nervosa with excessive exercise: a phenotype with close links to obsessive-compulsive disorder. Psychiatry Res. 2006;142(2-3):209-17. https://doi.org/10. 1016/j.psychres.2005.11.006.

10. Kostrzewa E, Eijkemans MJ, Kas MJ. The expression of excessive exercise co-segregates with the risk of developing an eating disorder in women. Psychiatry Res. 2013;210(3):1123-8. https:// doi.org/10.1016/j.psychres.2013.08.050.

11. Mainz V, Schulte-Ruther M, Fink GR, Herpertz-Dahlmann B, Konrad K. Structural brain abnormalities in adolescent anorexia nervosa before and after weight recovery and associated hormonal changes. Psychosom Med. 2012;74(6):574-82. https://doi. org/10.1097/PSY.0b013e31824ef10e.

12. Van den Eynde F, Suda M, Broadbent H, Guillaume S, Van den Eynde M, Steiger H, et al. Structural magnetic resonance imaging in eating disorders: a systematic review of voxel-based morphometry studies. Eur Eat Disord Rev. 2012;20(2):94-105. https://doi.org/10.1002/erv.1163.

13. Frank GK. Altered brain reward circuits in eating disorders: chicken or egg? Curr Psychiatry Rep. 2013;15(10):396. https:// doi.org/10.1007/s11920-013-0396-x.

14. Fuglset TS, Endestad T, Landro NI, Ro O. Brain structure alterations associated with weight changes in young females with anorexia nervosa: a case series. Neurocase. 2015;21(2):169-77. https://doi.org/10.1080/13554794.2013.878728.

15. Frintrop L, Trinh S, Liesbrock J, Leunissen C, Kempermann J, Etdoger $\mathrm{S}$, et al. The reduction of astrocytes and brain volume loss in anorexia nervosa-the impact of starvation and refeeding in a rodent model. Transl Psychiatry. 2019;9(1):159. https:// doi.org/10.1038/s41398-019-0493-7. Counters the prevailing assumption that neuronal loss underlies structural deficits in $\mathrm{AN}$ by providing evidence that astrocytes are the primary cell type affected. Recaptilates observations in humans that these deficits are reversed after weight restoration.

16. Hurley MM, Murlanova K, Macias LK, Sabir AI, O'Brien SC, Bhasin $\mathrm{H}$, et al. Activity-based anorexia disrupts systemic oxidative state and induces cortical mitochondrial fission in adolescent female rats. Int J Eat Disord. 2021;54(4):639-45. https://doi.org/ 10.1002/eat.23453.

17. Barona M, Brown M, Clark C, Frangou S, White T, Micali N. White matter alterations in anorexia nervosa: evidence from a voxel-based meta-analysis. Neurosci Biobehav Rev. 2019;100:28595. https://doi.org/10.1016/j.neubiorev.2019.03.002.

18. Finger FW. The effect of food deprivation and subsequent satiation upon general activity in the rat. J Comp Physiol Psychol. 1951;44(6):557-64. https://doi.org/10.1037/h0055692.

19. Dwyer DM, Boakes RA. Activity-based anorexia in rats as failure to adapt to a feeding schedule. Behav Neurosci. 1997;111(1):195-205.

20. Beeler JA, Mourra D, Zanca RM, Kalmbach A, Gellman C, Klein BY, et al. Vulnerable and resilient phenotypes in a mouse model of anorexia nervosa. Biol Psychiatry. 2020. https://doi. org/10.1016/j.biopsych.2020.06.030. By comparing female mice that are vulnerable vs. resilient to the ABA paradigm, demonstrates that the best predictor of weight loss in susceptible individual is hyperactivity in the light cycle, and not food intake. Provides evidence that hyperdopaminergia produced by genetic deficits in the dopamine transporter increases sensitivity to weight loss in the ABA paradigm.

21. Scharner S, Prinz P, Goebel-Stengel M, Lommel R, Kobelt P, Hofmann T, et al. Activity-based anorexia activates nesfatin-1 immunoreactive neurons in distinct brain nuclei of female rats. Brain Res. 2017;1677:33-46. https://doi.org/10.1016/j.brainres. 2017.09.024.

22. Scharner S, Stengel A. Animal models for anorexia nervosaa systematic review. Front Hum Neurosci. 2020;14: 596381. https://doi.org/10.3389/fnhum.2020.596381.

23. Barbarich-Marsteller NC, Underwood MD, Foltin RW, Myers MM, Walsh BT, Barrett JS, et al. Identifying novel phenotypes of vulnerability and resistance to activity-based anorexia in adolescent female rats. Int J Eat Disord. 2013;46(7):737-46. https:// doi.org/10.1002/eat.22149.

24. Pjetri E, de Haas R, de Jong S, Gelegen C, Oppelaar H, Verhagen LA, et al. Identifying predictors of activity based anorexia susceptibility in diverse genetic rodent populations. PLoS ONE. 2012;7(11): e50453. https://doi.org/10.1371/journal.pone.0050453.

25. Perez-Leighton CE, Grace M, Billington CJ, Kotz CM. Role of spontaneous physical activity in prediction of susceptibility to activity based anorexia in male and female rats. Physiol Behav. 2014;135:104-11. https://doi.org/10.1016/j.physbeh.2014.06. 001.

26. Wu H, van Kuyck K, Tambuyzer T, Luyten L, Aerts JM, Nuttin B. Rethinking food anticipatory activity in the activity-based anorexia rat model. Sci Rep. 2014;4:3929. https://doi.org/10. 1038/srep03929.

27.• Milton LK, Mirabella PN, Greaves E, Spanswick DC, van den Buuse M, Oldfield BJ, et al. Suppression of corticostriatal circuit activity improves cognitive flexibility and prevents body weight loss in activity-based anorexia in rats. Biol Psychiatry. 2020. https://doi.org/10.1016/j.biopsych.2020.06.022. Uses pathway-specific chemogenetics to selectively modulate activity in medial prefrontal cortex to nucleus accumbens circuits. Stimulation recapitulates links between increased susceptibility to ABA and cognitive inflexibility. These phenotypes are reversed when this pathway is inhibited, providing evidence that this circuit contributes to pathophysiological responses to the ABA paradigm. Resilience is reflected in increased food intake, rather than reduced activity, 
consistent with the idea that failure to adapt to the restricted feeding schedule is the primary deficit in ABA mice.

28. Challet E. Interactions between light, mealtime and calorie restriction to control daily timing in mammals. J Comp Physiol B. 2010;180(5):631-44. https://doi.org/10.1007/ s00360-010-0451-4.

29. Guisinger S. Adapted to flee famine: adding an evolutionary perspective on anorexia nervosa. Psychol Rev. 2003;110(4):745-61. https://doi.org/10.1037/0033-295X.110.4.745.

30. Adan RA, Hillebrand JJ, Danner UN, Cardona Cano S, Kas MJ, Verhagen LA. Neurobiology driving hyperactivity in activitybased anorexia. Curr Top Behav Neurosci. 2011;6:229-50. https://doi.org/10.1007/7854_2010_77.

31. Aoki C, Chowdhury TG, Wable GS, Chen YW. Synaptic changes in the hippocampus of adolescent female rodents associated with resilience to anxiety and suppression of food restriction-evoked hyperactivity in an animal model for anorexia nervosa. Brain Res. 2017;1654(Pt B):102-15. https://doi.org/10.1016/j.brainres. 2016.01.019.

32. Bilash OM, Actor-Engel HS, Sherpa AD, Chen YW, Aoki C. Suppression of food restriction-evoked hyperactivity in activitybased anorexia animal model through glutamate transporters GLT-1 at excitatory synapses in the hippocampus. Synapse. 2021;75(7):e22197. https://doi.org/10.1002/syn.22197. Provides evidence that hyperactivity in the hippocampus of female mice subjected to the $A B A$ paradigm is the consequence of decreased levels of the astrocytic glutamate transporter GLT-1.

33.• Jia YF, Wininger K, Peyton L, Ho AM, Choi DS. Astrocytic glutamate transporter 1 (GLT1) deficient mice exhibit repetitive behaviors. Behav Brain Res. 2021;396:112906. https://doi.org/ 10.1016/j.bbr.2020.112906. Uses a conditional loss of functional approach to demonstrate that decreased levels of the astrocytic glutamate transporter GLT-1deficiency promote OCD-like repetitive behaviors.

34. Gomez-Galan M, Femenia T, Aberg E, Graae L, Van Eeckhaut A, Smolders I, et al. Running opposes the effects of social isolation on synaptic plasticity and transmission in a rat model of depression. PLoS ONE. 2016;11(10):e0165071. https://doi.org/ 10.1371/journal.pone.0165071.

35. Ribeiro LC, Quincozes-Santos A, Leite MC, Abib RT, Kleinkauf-Rocha J, Biasibetti R, et al. Caloric restriction increases hippocampal glutamate uptake and glutamine synthetase activity in Wistar rats. Neurosci Res. 2009;64(3):330-4. https://doi.org/10.1016/j.neures.2009.04.004.

36. Frank GK, Bailer UF, Henry SE, Drevets W, Meltzer CC, Price JC, et al. Increased dopamine D2/D3 receptor binding after recovery from anorexia nervosa measured by positron emission tomography and [11c]raclopride. Biol Psychiatry. 2005;58(11):908-12. S0006-3223(05)00576-7[pii]. https:// doi.org/10.1016/j.biopsych.2005.05.003.

37. Gallo EF, Salling MC, Feng B, Moron JA, Harrison NL, Javitch $\mathrm{JA}$, et al. Upregulation of dopamine $\mathrm{D} 2$ receptors in the nucleus accumbens indirect pathway increases locomotion but does not reduce alcohol consumption. Neuropsychopharmacology. 2015;40(7):1609-18. https://doi.org/10.1038/npp.2015.11.

38. Gallo EF, Meszaros J, Sherman JD, Chohan MO, Teboul E, Choi $\mathrm{CS}$, et al. Accumbens dopamine D2 receptors increase motivation by decreasing inhibitory transmission to the ventral pallidum. Nat Commun. 2018;9(1):1086. https://doi.org/10.1038/ s41467-018-03272-2.

39.•• Welch AC, Zhang J, Lyu J, McMurray MS, Javitch JA, Kellendonk $\mathrm{C}$, et al. Dopamine D2 receptor overexpression in the nucleus accumbens core induces robust weight loss during scheduled fasting selectively in female mice. Mol Psychiatry. 2019. https://doi. org/10.1038/s41380-019-0633-8. Uses a targeted overexpression approach to address the issue of whether increased D2R expression seen in the anteroventral striatum after weight restoration plays a causative role in $\mathrm{AN}$ or reflects an adaptation to the acute illness. The finding that $\mathrm{D} 2 \mathrm{R}$ overexpression in the nucleus accumbens increases running activity and weight loss in females supports the idea that it directly contributes to susceptibility to the ABA paradigm.

40. Bulik CM, Sullivan PF, Tozzi F, Furberg H, Lichtenstein P, Pedersen NL. Prevalence, heritability, and prospective risk factors for anorexia nervosa. Arch Gen Psychiatry. 2006;63(3):305-312, 63/3/305[pii]. https://doi.org/10. 1001/archpsyc.63.3.305.

41. Hoek HW. Incidence, prevalence and mortality of anorexia nervosa and other eating disorders. Curr Opin Psychiatry. 2006;19(4):389-94. https://doi.org/10.1097/01.yco.0000228759. 95237.7800001504-200607000-00010[pii].

42. Cha J, Ide JS, Bowman FD, Simpson HB, Posner J, Steinglass JE. Abnormal reward circuitry in anorexia nervosa: a longitudinal, multimodal MRI study. Hum Brain Mapp. 2016;37(11):383546. https://doi.org/10.1002/hbm.23279.

43. Block AE, Dhanji H, Thompson-Tardif SF, Floresco SB. Thalamicprefrontal cortical-ventral striatal circuitry mediates dissociable components of strategy set shifting. Cereb Cortex. 2007;17(7):1625-36. https://doi.org/10.1093/cercor/bhl073.

44. Piao C, Deng X, Wang X, Yuan Y, Liu Z, Liang J. Altered function in medial prefrontal cortex and nucleus accumbens links to stress-induced behavioral inflexibility. Behav Brain Res. 2017;317:16-26. https://doi.org/10.1016/j.bbr.2016.09.017.

45. Tchanturia K, Morris RG, Anderluh MB, Collier DA, Nikolaou $\mathrm{V}$, Treasure J. Set shifting in anorexia nervosa: an examination before and after weight gain, in full recovery and relationship to childhood and adult OCPD traits. J Psychiatr Res. 2004;38(5):545-52. https://doi.org/10.1016/j.jpsychires.2004. 03.001 .

46. Holliday J, Tchanturia K, Landau S, Collier D, Treasure J. Is impaired set-shifting an endophenotype of anorexia nervosa? Am J Psychiatry. 2005;162(12):2269-75. https://doi.org/10. 1176/appi.ajp.162.12.2269.

47. Steinglass JE, Walsh BT, Stern Y. Set shifting deficit in anorexia nervosa. J Int Neuropsychol Soc. 2006;12(3):431-5. https://doi. org/10.1017/s1355617706060528.

48. Allen PJ, Jimerson DC, Kanarek RB, Kocsis B. Impaired reversal learning in an animal model of anorexia nervosa. Physiol Behav. 2017;179:313-8. https://doi.org/10.1016/j.physbeh.2017.06.013.

49. Kanarek RB, Collier GH. Self-starvation: a problem of overriding the satiety signal? Physiol Behav. 1983;30(2):307-11. https://doi.org/10.1016/0031-9384(83)90024-0.

50. Miletta MC, Iyilikci O, Shanabrough M, Sestan-Pesa M, Cammisa A, Zeiss CJ, et al. AgRP neurons control compulsive exercise and survival in an activity-based anorexia model. Nat Metab. 2020;2(11):1204-11. https://doi.org/10.1038/ s42255-020-00300-8.

51. Gyertyan I. Analysis of the marble burying response: marbles serve to measure digging rather than evoke burying. Behav Pharmacol. 1995;6(1):24-31.

52. Deacon RM. Digging and marble burying in mice: simple methods for in vivo identification of biological impacts. Nat Protoc. 2006;1(1):122-4. https://doi.org/10.1038/nprot.2006.20.

53. Witkin JM. Animal models of obsessive-compulsive disorder. Curr Protoc Neurosci. 2008;Chapter 9:Unit 9 30. https://doi.org/ 10.1002/0471142301.ns0930s45.

54. Anderluh MB, Tchanturia K, Rabe-Hesketh S, Treasure J. Childhood obsessive-compulsive personality traits in adult women with eating disorders: defining a broader eating disorder phenotype. Am J Psychiatry. 2003;160(2):242-7. https://doi.org/10. 1176/appi.ajp.160.2.242. 
55. Bohon C, Weinbach N, Lock J. Performance and brain activity during the Wisconsin Card Sorting Test in adolescents with obsessive-compulsive disorder and adolescents with weight-restored anorexia nervosa. Eur Child Adolesc Psychiatry. 2020;29(2):217-26. https://doi.org/10.1007/ s00787-019-01350-4.

56. Montigny C, Castellanos-Ryan N, Whelan R, Banaschewski T, Barker GJ, Buchel C, et al. A phenotypic structure and neural correlates of compulsive behaviors in adolescents. PLoS ONE. 2013;8(11): e80151. https://doi.org/10.1371/journal.pone.0080151.

57. Gutierrez E, Vazquez R, Boakes RA. Activity-based anorexia: ambient temperature has been a neglected factor. Psychon Bull Rev. 2002;9(2):239-49. https://doi.org/10.3758/bf03196278.

58. Hillebrand JJ, Koeners MP, de Rijke CE, Kas MJ, Adan RA. Leptin treatment in activity-based anorexia. Biol Psychiatry. 2005;58(2):165-71. https://doi.org/10.1016/j.biopsych.2005. 03.011 .

59. Hillebrand JJ, de Rijke CE, Brakkee JH, Kas MJ, Adan RA. Voluntary access to a warm plate reduces hyperactivity in activitybased anorexia. Physiol Behav. 2005;85(2):151-7. https://doi. org/10.1016/j.physbeh.2005.03.017.

60. Wable GS, Min JY, Chen YW, Aoki C. Anxiety is correlated with running in adolescent female mice undergoing activitybased anorexia. Behav Neurosci. 2015;129(2):170-82. https:// doi.org/10.1037/bne0000040.

61. Milton LK, Oldfield BJ, Foldi CJ. Evaluating anhedonia in the activity-based anorexia (ABA) rat model. Physiol Behav. 2018;194:324-32. https://doi.org/10.1016/j.physbeh.2018.06.023.

62. Chen YW, Actor-Engel H, Aoki C. alpha4-GABAA receptors of hippocampal pyramidal neurons are associated with resilience against activity-based anorexia for adolescent female mice but not for males. Mol Cell Neurosci. 2018;90:33-48. https://doi. org/10.1016/j.mcn.2018.04.008.

63. Farinetti A, Aspesi D, Marraudino M, Marzola E, Amianto F, Abbate-Daga G, et al. Sexually dimorphic behavioral effects of maternal separation in anorexic rats. Dev Psychobiol. 2020;62(3):297-309. https://doi.org/10.1002/dev.21909.

64. Penas-Lledo E, Vaz Leal FJ, Waller G. Excessive exercise in anorexia nervosa and bulimia nervosa: relation to eating characteristics and general psychopathology. Int J Eat Disord. 2002;31(4):370-5. https://doi.org/10.1002/eat.10042.

65. Holtkamp K, Hebebrand J, Herpertz-Dahlmann B. The contribution of anxiety and food restriction on physical activity levels in acute anorexia nervosa. Int J Eat Disord. 2004;36(2):163-71. https://doi.org/10.1002/eat.20035.

66. Duncan L, Yilmaz Z, Gaspar H, Walters R, Goldstein J, Anttila $\mathrm{V}$, et al. Significant locus and metabolic genetic correlations revealed in genome-wide association study of anorexia nervosa. Am J Psychiatry. 2017;174(9):850-8. https://doi.org/10.1176/ appi.ajp.2017.16121402.

67. Watson HJ, Yilmaz Z, Thornton LM, Hubel C, Coleman JRI, Gaspar HA, et al. Genome-wide association study identifies eight risk loci and implicates metabo-psychiatric origins for anorexia nervosa. Nat Genet. 2019;51(8):1207-14. https://doi. org/10.1038/s41588-019-0439-2.

Publisher's Note Springer Nature remains neutral with regard to jurisdictional claims in published maps and institutional affiliations. 